\title{
Surface characteristics of low carbon steel JISG3101SS400 after sandblasting process by steel grit G25
}

\author{
M. Muslimin*****, Azam Milah Muhamad*, Farid Triawan** and Asep Bayu Dani \\ Nandiyanto $* * *$ \\ *Department of Mechanical Engineering, Politeknik Negeri Jakarta, Jl. Prof. Dr. G.A Siwabessy, UI Campus, Depok, Indonesia. \\ **Faculty of Engineering and Technology, Sampoerna University, Jl. Raya Pasar Minggu, Kav.16, Pancoran, Jakarta, Indonesia. \\ *** Departemen Kimia, Universitas Pendidikan Indonesia, Jl. Dr. Setiabudi 229, Bandung, Indonesia. \\ ****Corresponding Author: muslimin@mesin.pnj.ac.id
}

Submitted : 31/03/2020

Revised : :10/10/2020

Accepted :21/10/2020

\begin{abstract}
This research aims to study the surface characteristics of low carbon steel JISG3101SS400 processed by sandblasting using steel grit G25. The sandblasting process is conducted at a fixed nozzle pressure of 5 bars and pressure angle of $90^{\circ}$, and varying nozzle-to-surface distances at 15,25 , and $30 \mathrm{~cm}$, and blasting durations of 25 , 45, and $120 \mathrm{~s}$. Surface characterization is firstly carried out by conducting observation on the surface's morphology by a scanning electron microscope (SEM) and chemical composition by an energy dispersive X-ray Spectroscopy (EDS). Subsequently, visual inspection and measurement on surface roughness and hardness profile identification by Rockwell and micro-Vickers hardness tests are conducted. A paint thickness test using ASTMD7091 was undertaken to observe the surface characteristics related to the coating process. Based on the result, the SEM analysis found valleys, granules, micro-cracks, and grits embedded on the surface. The visual inspection shows that the roughness is within the range in ISO8501 with values being Ra18.1 and Ra21.4 $\mu \mathrm{m}$. The hardened layer exhibits a maximum hardness value of $332 \mathrm{HV}$ and a depth of more than $50 \mu \mathrm{m}$ by sandblasting parameters of $15 \mathrm{~cm}$ distance and $120 \mathrm{~s}$ duration. Both roughness and hardness profiles are confirmed, increasing with closer nozzle-to-surface distance and longer blast duration. It is concluded that sandblasting using steel grit G25 is effective in improving the mechanical strength and surface hardness of low carbon steel SS400. These mechanical properties are essential in the paint coating of machinery applications such as pumps, tanks, ships, and pipelines.
\end{abstract}

Keywords: Sandblasting; Steel grit G25; Low carbon steel SS400; Surface roughness; Surface hardness.

\section{INTRODUCTION}

Surface treatment is widely used in many engineering applications to improve the strength and lifetime of a mechanical component under particular operating conditions. The purpose of surface treatment is usually to increase the strength, hardness, corrosion resistance, wear resistance, and fatigue life (Khorasanizadeh, 2010, 2005; 
Triawan et al., 2018; Trisnanto et al., 2019; Saptaji et al., 2019; and Bedjaoui et al., 2019). Sandblasting is one of the surface treatments that is usually applied for modifying the component's strength by improving the surface quality (Khorasanizadeh, 2010; Saptaji et al., 2019; Bedjaoui et al., 2019; and Arifvianto et al., 2010). Sandblasting uses a high-velocity abrasive particle with pressurized air that can clean a surface from rust, paint, and oil. Sandblasting also can create a roughness profile on the metal surface to ease the color to stick perfectly (Khorasanizadeh, 2010). Moreover, surface roughing can increase the surface area and provide undercuts that provide mechanical interlocking between substrate and coating to increase bonding strength (Bobzin et al., 2015). The blasting particles that are commonly used are $\mathrm{Al}_{2} \mathrm{O}_{3}, \mathrm{ZrO}_{2}, \mathrm{TiO}_{2}, \mathrm{SiO}_{2}$, and bio-ceramic. The particle should be made of hard and non-toxic materials and can be quickly blasted by the compressed gas flow. The high-pressure collision of abrasive materials causes a plastic deformation on the surface of the target material. The deformation results in unique surface topography and properties depending on the blasting parameters, such as nozzle pressure, nozzle-to-surface distance, and blasting duration (Arifvianto et al., 2012; Ho et al., 2015).

Some previous works reported the effect of various blasting particles on the target materials, such as the impact of continuous usage of $\mathrm{Al}_{2} \mathrm{O} 3$ on medical grade 316 L stainless steel (Arifvianto et al., 2012), $\mathrm{Al}_{2} \mathrm{O}_{3}$ abrasive material with a diameter of $0.35 \mathrm{~mm}$ (Miao et al., 2017), and the combination of abrasive blasting materials $\left(\mathrm{ZrO}_{2}\right.$ with $\mathrm{SiO}_{2}(125-250 \mu \mathrm{m})$ and $\mathrm{Al}_{2} \mathrm{O} 3(750 \mu \mathrm{m})$, when blasted against the target metal of $316 \mathrm{LVM}$ stainless steel) (Multigner et al., 2010). From those works, $\mathrm{Al} 2 \mathrm{O} 3$ could be considered as a prospective material used in the sandblasting process. However, these particles have some drawbacks such as being expensive and dusty, and they produce irregular cavities, scratches, and coarse morphology (Arifvianto et al., 2012; Chander et al., 2009). $\mathrm{SiO}_{2}$ also can be used. This material is largely available even it can be produced from agricultural waste (Permatasari et al., 2016; Nandiyanto et al., 2016; Nandiyanto, 2018; and Ragadhita et al., 2019). However, some problems similar to $\mathrm{Al}_{2} \mathrm{O}_{3}$ persist.

The present work evaluates the application of steel grit G25, which can be considered as an alternative sandblasting particle that is relatively cheaper and cleaner than alumina. The target material, low carbon steel JISG3101SS400 is selected due to its frequent application in engineering machinery. There is still limited research reported about the effect of steel grit G25 on the surface characteristics of low carbon steel SS400 specimens after the sandblasting process. Observation on the surface by the scanning electron microscope (SEM) and the energy dispersive X-ray Spectroscopy (EDS) is done to understand the surface morphology and chemical composition. Visual roughness inspection, surface roughness measurement, and hardness tests are carried out to assess the effectiveness of the particle in creating a hardened layer. A paint thickness test is then applied to investigate the effectivity of the surface characteristics of the sandblasting process, showing that the potential application of steel grit G25 for sandblasting applications can be assessed.

\section{MATERIALS AND METHOD}

The specimen used as the target material was a plate of low carbon steel JISG3101SS400 with chemical composition, as shown in Table1. This material is chosen because it is commonly used as a structural material in machinery, such as pump, ship, tank, and pipeline. The specimen was in the plate shape with a dimension of $150 \mathrm{x}$ $150 \times 6 \mathrm{~mm}$, in which $6 \mathrm{~mm}$ is the thickness. The blasting particle used is steel grit G25 with chemical composition and specification tabulated in Tables 2 and 3. Figure 1 shows the G25 steel grits used in the experiment. 
Table 1. Chemical composition of JISG3101 SS400.

\begin{tabular}{|c|c|c|c|c|c|c|}
\hline Elements (max) & $\mathrm{Fe}$ & $\mathrm{C}$ & $\mathrm{Si}$ & $\mathrm{Mn}$ & $\mathrm{P}$ & $\mathrm{S}$ \\
\hline Weight (\%) & 0.81 & $0.0066-0.026$ & - & 0.206 & 0.050 & 0.050 \\
\hline
\end{tabular}

Table 2. Chemical composition of steel grit G25.

\begin{tabular}{|l|c|c|c|c|c|}
\hline Material & Elements & $\mathrm{C}$ & $\mathrm{Si}$ & $\mathrm{S}$ & $\mathrm{P}$ \\
\hline Steel grit G25 & Min. & 0.8 & 0.4 & - & - \\
\hline & Max. & 1.2 & - & 0.04 & 0.04 \\
\hline
\end{tabular}

Table 3. Properties of steel grit G25.

\begin{tabular}{|c|c|}
\hline Shapes & Angular \\
\hline Grain color & Grey \\
\hline density & $7.4 \mathrm{~kg} / \mathrm{dm}^{3}$ \\
\hline Microstructure & Tempered martensite \\
\hline Hardness & $>60 \mathrm{HRC}$ \\
\hline Grain size & $0.71-1.19 \mathrm{~mm}$ \\
\hline
\end{tabular}

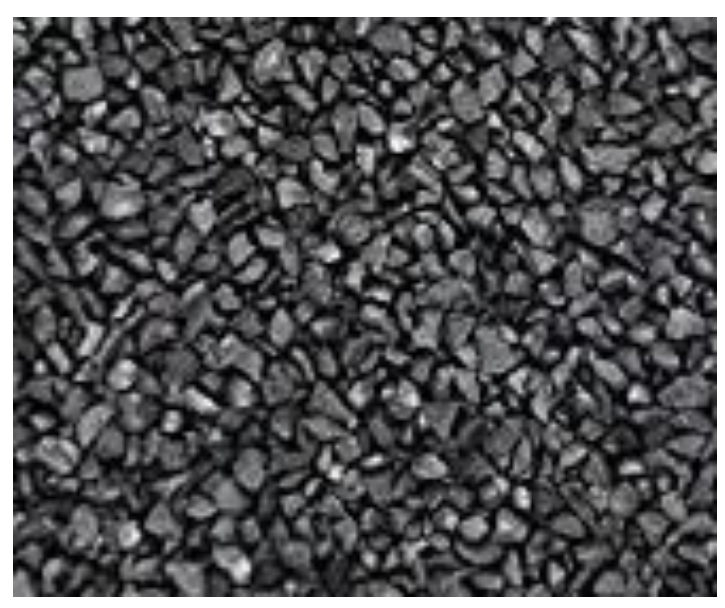

Figure 1. Steel grit G25 particle (particle size: 0.71- $1.19 \mathrm{~mm}$ ). 
The sandblasting processes were carried out under several predetermined parameters, as tabulated in Table 4 . The experimental setup is shown in Figure 2. During the sandblasting process, the nozzle pressure was kept constant at 5 bars, and the angle of blasting was maintained at $90^{\circ}$ to the surface. The varying parameters were the nozzle-to-surface distance and blasting duration. The distance between nozzle and surface of 15, 25, and $30 \mathrm{~cm}$ and the blasting duration of 25, 45, and $120 \mathrm{~s}$ were implemented. Thus, a total of nine specimens were tested in the experiment.

Table 4. Sandblasting experimental condition.

\begin{tabular}{|c|c|c|}
\hline Nozzle pressure/blasting angle & Nozzle-to-surface distance (cm) & Blasting duration (s) \\
\hline \multirow{3}{*}{5 bars $/ 90^{\circ}$} & 15 & 25 \\
\cline { 2 - 3 } & 25 & 45 \\
\cline { 2 - 3 } & 30 & 120 \\
\hline
\end{tabular}



Figure 2. Schematic figure of sandblasting setup.

After the sandblasting process, surface characterization on every specimen was carried out. Firstly, surface observations by SEM and EDS, using the Phenom Pharos Desktop SEM machine, were conducted to analyze the surface morphology and chemical composition. Subsequently, to understand the surface roughness and hardness, visual roughness inspection based on ISO8501 and roughness measurement based on ASTMD7127-13 were performed. Moreover, hardness measurements by Rockwell and Micro-Vickers hardness tests were carried out. The Rockwell hardness test of ASTME18-15ScaleB was implemented directly (without ground and polish process) to measure the surface hardness profile across the surface from left to right at 25, 45, 65, 85, 105, and 125 $\mathrm{cm}$ in one straight line. The micro-Vickers hardness test was done using ASTME384-11 with 10g float at depths of $50,100,150,200,250$, and $300 \mu \mathrm{m}$ to understand the extent of the hardened layer. A paint thickness test is then applied to measure the effectivity of the surface characteristics of the sandblasting process. 


\section{RESULTS AND DISCUSSION}

\section{Surface Morphology}

The surface morphology of SS400 steel after the sandblasting process using steel grit G25 was analyzed using a Scanning Electron Microscope (SEM). To investigate the experiment parameter effects on surface morphology, SEM was applied into two-experiment setup, that is, experiment with nozzle-to-surface of $15 \mathrm{~cm}$ (the shortest distance), blasting time of $120 \mathrm{~s}$ (the longest time), experiment setup with nozzle-to-surface of $30 \mathrm{~cm}$ (the most extended length), and blasting time of $25 \mathrm{~s}$ (the shortest time). The typical surface morphology images observed by SEM in these setups are shown in Figures 3 and 4. Figure 3 shows the SEM image resulted from the experimental setup of $30 \mathrm{~cm}$ nozzle distance and $25 \mathrm{~s}$ blasting time. On the other hand, Figure 4 shows the SEM image produced from the sandblasting process of $15 \mathrm{~cm}$ nozzle distance and $120 \mathrm{~s}$ blasting time. Granular, valleys, grit embedded on the surface, and micro-cracks are observed in both pictures. The valleys are formed by the high impact energy of particle collision on the surface. The micro-scale roughness observed on the surface was created by the abrasive mechanism occurring during the particle collision, causing the surface to be partially cut. Based on the SEM analysis, the shortest distance and the most prolonged blasting duration result in deeper valley formations on the surface (see Figure 4). On the other hand, shallow valleys formations on the surface result from the long distance and the short blasting duration result (see Figure 3). The micro-cracks structure is most likely due to collision (impact) during the sandblasting process. The numbers of micro-cracks and valleys were affected by the intensity of the abrasive material that hits the surface. Moreover, some grits can embed on the surface during the blasting process because grit attaches to the soft area of the surface.

Figure 5 shows the typical chemical composition of the specimen surface after the sandblasting process at 30 $\mathrm{cm}$ blasting distance and $25 \mathrm{~s}$ blasting time. Based on the $\mathrm{EDS}$ result, the chemical content is $6.62 \% \mathrm{C}, 17.20 \% \mathrm{O}$, and $76.14 \% \mathrm{Fe}$. It was found that by employing steel grit G25 as the abrasive material, besides a collision, steel grit was also deposited on the surface during the sandblasting process. As a result, the carbon content increases in the surface.

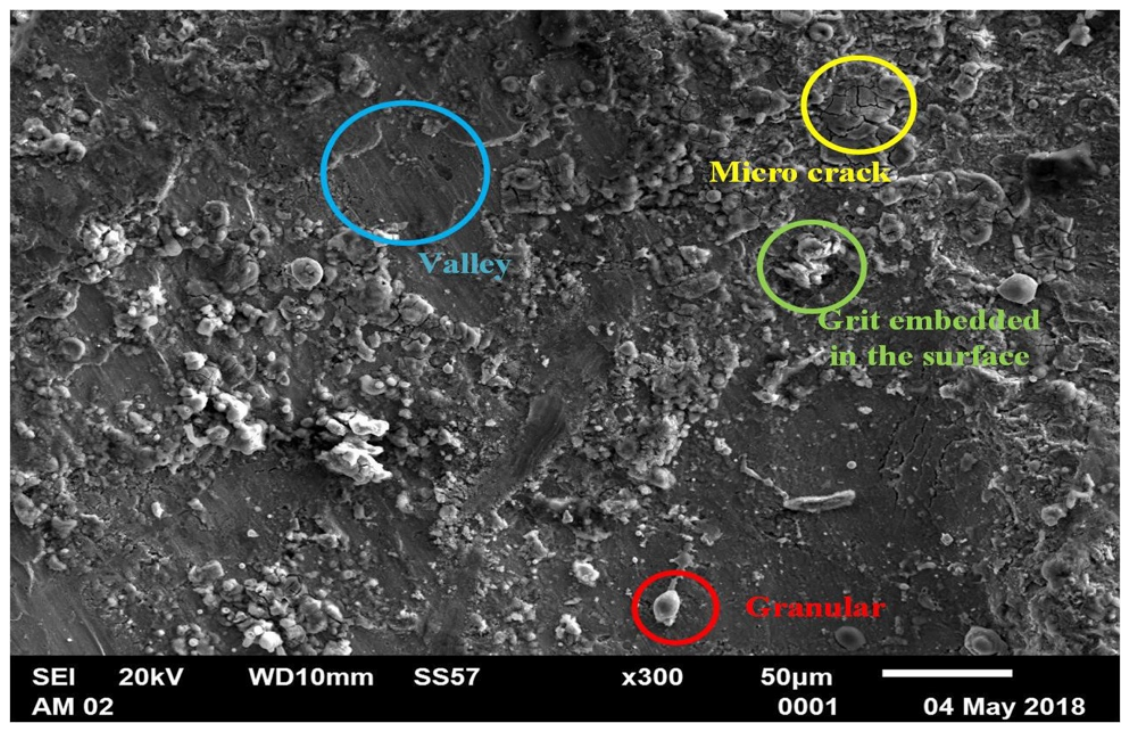

Figure 3. SEM image of surface morphology with the nozzle-to-surface distance of $30 \mathrm{~cm}$ and blasting duration of $25 \mathrm{~s}$. 


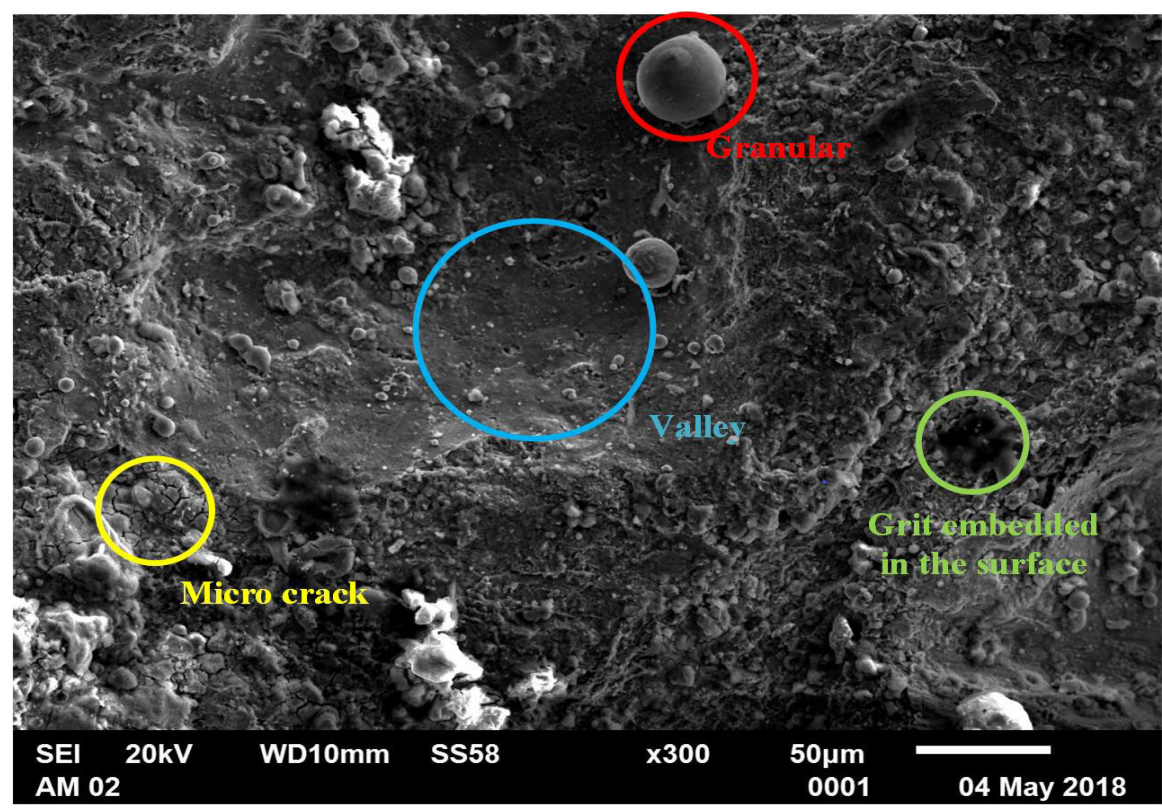

Figure 4. SEM image of surface morphology with the nozzle-to-surface distance of $15 \mathrm{~cm}$ and blasting duration of $120 \mathrm{~s}$

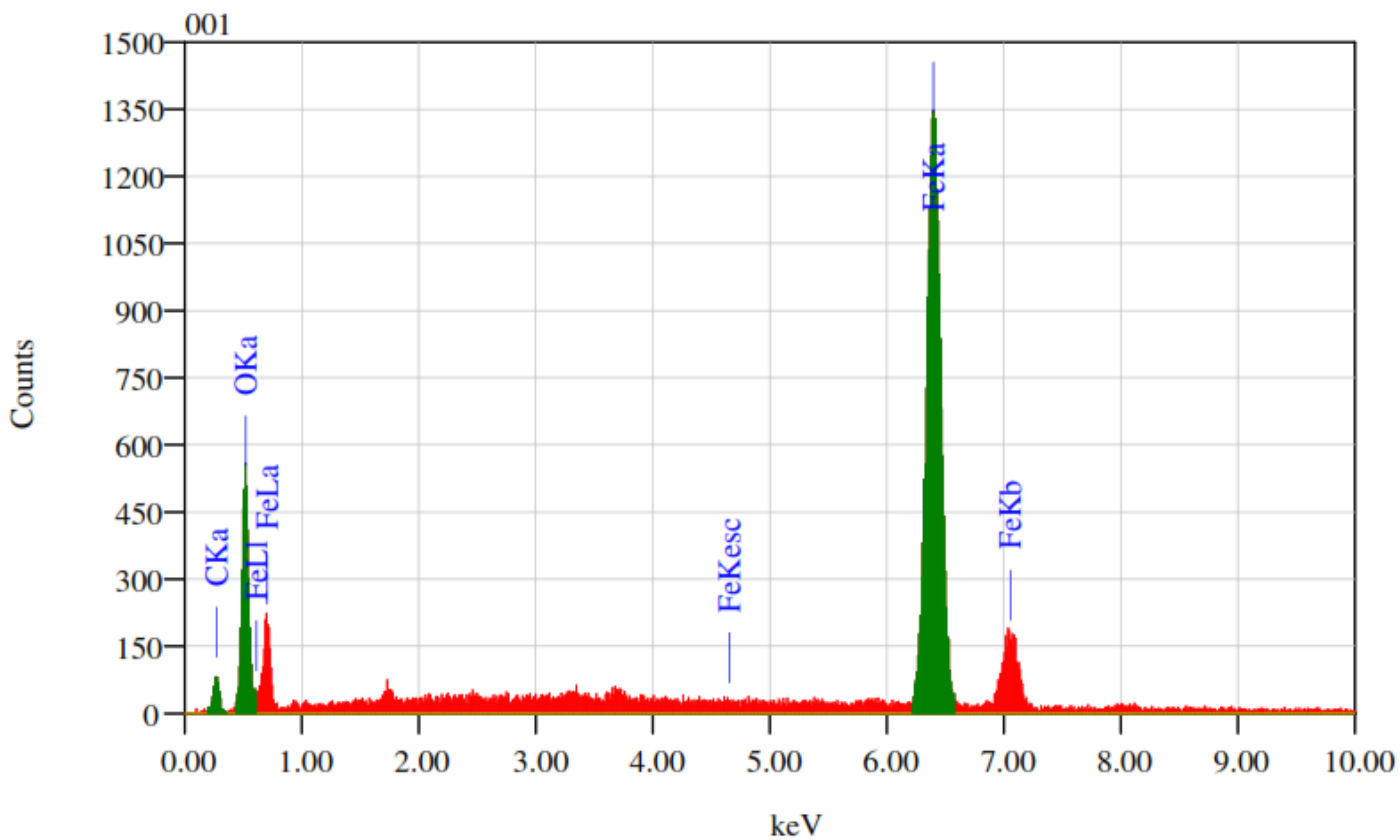

Figure 5. Chemical composition analysis by Energy Dispersive Spectrometry (EDS) with nozzle-to-surface distance of $30 \mathrm{~cm}$ and blasting duration of $25 \mathrm{~s}$. 
Figure 6 shows the typical chemical composition of the specimen surface after the sandblasting process at 15 $\mathrm{cm}$ blasting distance (the shortest distance) and $120 \mathrm{~s}$ time (the most prolonged duration).Based on the EDS result, the chemical content is $8.60 \%$ of $\mathrm{C}, 17.84 \%$ of $\mathrm{O}$, and $73.55 \%$ of Fe. It was found that the carbon deposited on the surface in this experimental setup is higher than the carbon content of the experimental setup of the sandblasting process at $30 \mathrm{~cm}$ blasting distance and $25 \mathrm{~s}$ time.

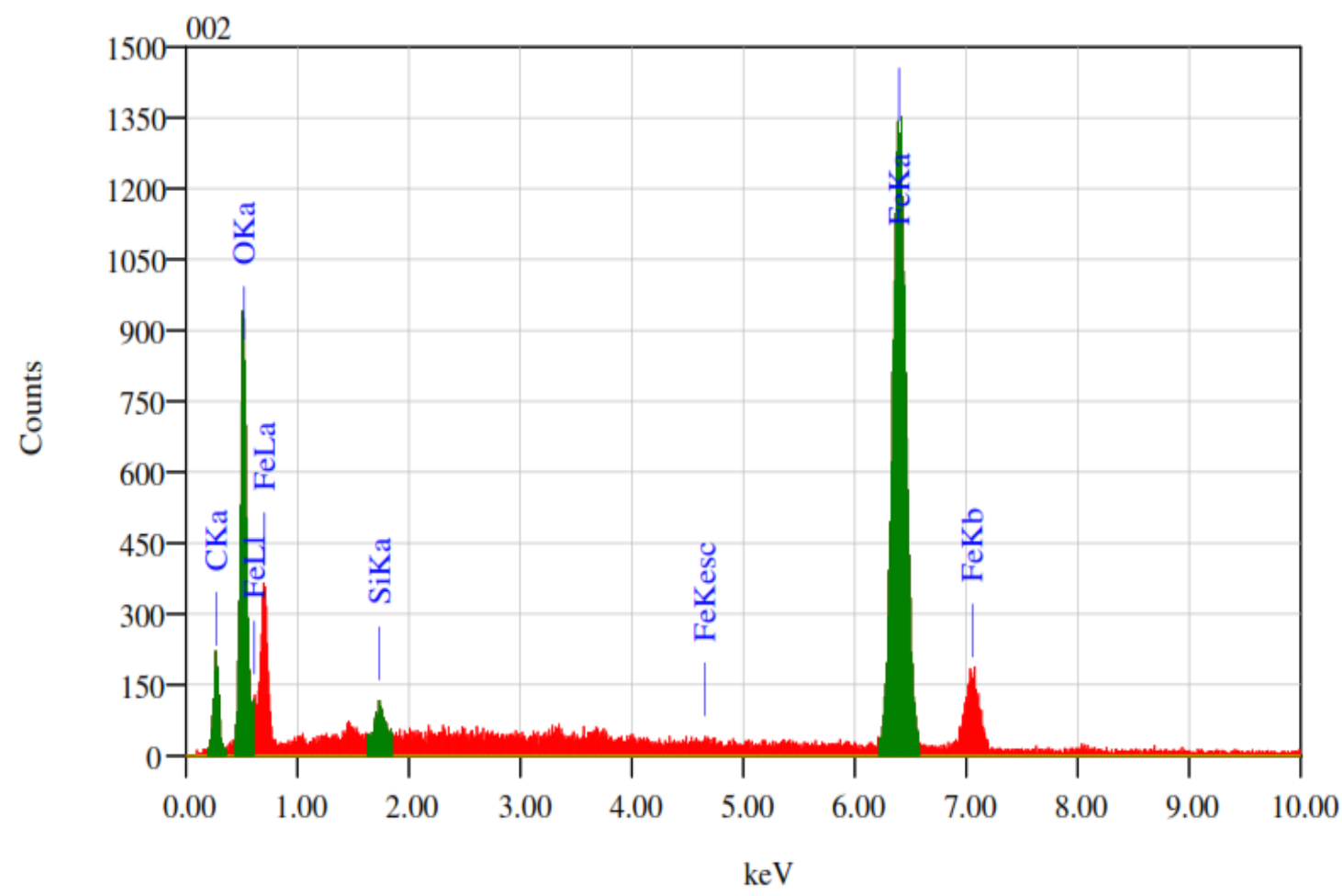

Figure 6. Chemical composition analysis by Energy Dispersive Spectrometry (EDS) with nozzle-to-surface distance of $15 \mathrm{~cm}$ and blasting duration of $120 \mathrm{~s}$

\section{Surface Cleanliness}

Surface cleanliness is essential in surface preparation of steel structure by paint coating. ISO-8501 accomplishes the visual surface cleanliness test. According to this standard, blasting surface cleanliness is Sa grade. Figure 7 shows the typical surface cleanliness after sandblasting processes. Figures 7(a), (b), and (c) can be classified as Sa2, $\mathrm{Sa}_{2}^{1} / 2$, and Sa3, respectively. The $\mathrm{Sa} 2$ grade was obtained by sandblasting at nozzle-to-surface distance of $15 \mathrm{~cm}$ regardless of the duration. The Sa2 ${ }^{1} / 2$ surface was obtained at nozzle-to-surface lengths of 25 and $30 \mathrm{~cm}$ with blasting durations of 45 and $120 \mathrm{~s}$. The Sa3 surface was created at nozzle-to-surface distances of 25 and $30 \mathrm{~cm}$ with a blasting duration of $25 \mathrm{~s}$. 


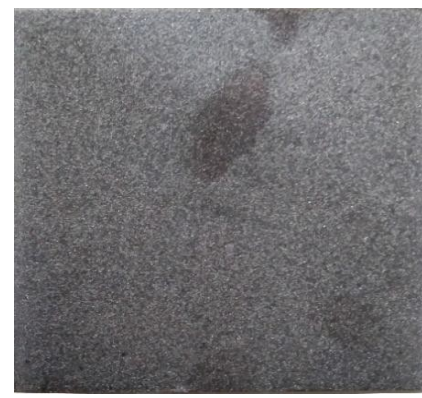

(a) $\mathrm{Sa} 2$

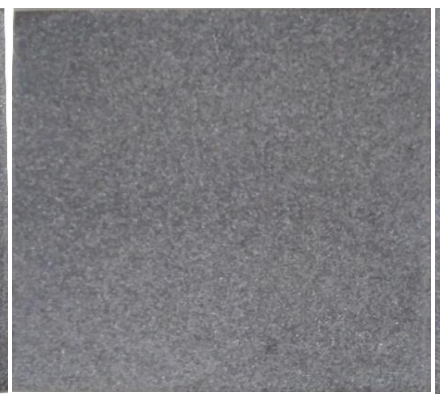

(b) $\mathrm{Sa} 2 \frac{1}{2}$



(c) $\mathrm{Sa} 3$

Figure 7. Visual inspection of surface roughness (length $150 \mathrm{~mm} x$ width $150 \mathrm{~mm}$ ). Sa2 is thorough blast-cleaning; Sa2 1/2 is very thorough blast-cleaning; Sa3 is blast-cleaning to visually clean steel.

\section{Surface Roughness}

The surface roughness measurement results are summarized in Figure 8. The highest roughness was Ra21.4 $\mu \mathrm{m}$ (roughness level of M10-M11), which was obtained from nozzle- to-surface distance of $15 \mathrm{~cm}$ and blasting duration of $120 \mathrm{~s}$. On the other hand, the lowest value of Ra18.1 $\mu \mathrm{m}$ (roughness level of M10-M11) was obtained from the sandblasting process at nozzle-to-surface distance of $30 \mathrm{~cm}$ and blasting duration of $25 \mathrm{~s}$. In other words, the closer the distance between nozzle and surface is, the higher the surface roughness can be.

These results are expected because a closer distance of nozzle and surface will produce a higher momentum between particle and exterior, generating high impact energy. Thus, it was observed that the surface roughness tends to be smoother as the nozzle-surface distance increases, as also described by Hoetal (2015). The blasting duration also contributed to the increase in surface roughness. It was observed that the longer the material's surface was exposed to the sandblasting process, the more the collision and erosion occurred. Therefore, the surface roughness of the material increases proportionally with increasing blasting duration. Based on these results, it can be concluded that roughness tests results are in good agreement.

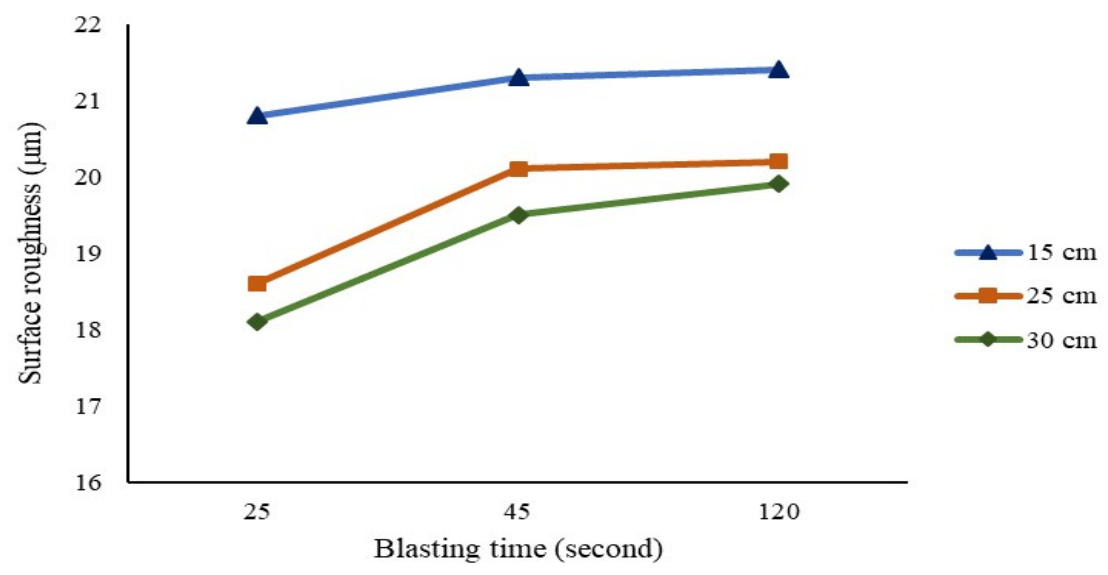

Figure 8. Surface roughness measurement results at different variables of sandblasting. 


\section{Surface Hardness}

The results of Rockwell hardness tests on specimens sandblasted at $15 \mathrm{~cm}$ blasting distance and 15, 25, and $120 \mathrm{~s}$ blasting durations are plotted in Figure 9. The surface hardness could be improved by plastic deformation. The hardness profile across the surface is uniformly distributed from one edge to another. The generation of residual stress produces increasing surface hardness due to the collision of particles with the surface (Saptaji et al., 2019). The high-velocity collision between steel grit and surface also produced strain hardening on the surface that can increase the surface hardness.

Measurement result on the hardness profile in-depth direction is shown in Figure 10. Based on the outcome, it was confirmed that the sandblasted surface was hardened until a certain depth before finally reaching the hardness of the base metal. This condition is the affected layer by heat generated due to colliding particles, while the base metal did not receive any heat. The micro hardness increases by decreasing the nozzle-surface distance and increasing the blasting duration. The maximum value of micro hardness was found to be $332 \mathrm{HV}$ (equal to 108HRB) with a depth of more than $50 \mu \mathrm{m}$ for the specimen that was processed at $15 \mathrm{~cm}$ blasting distance and 120 s duration.

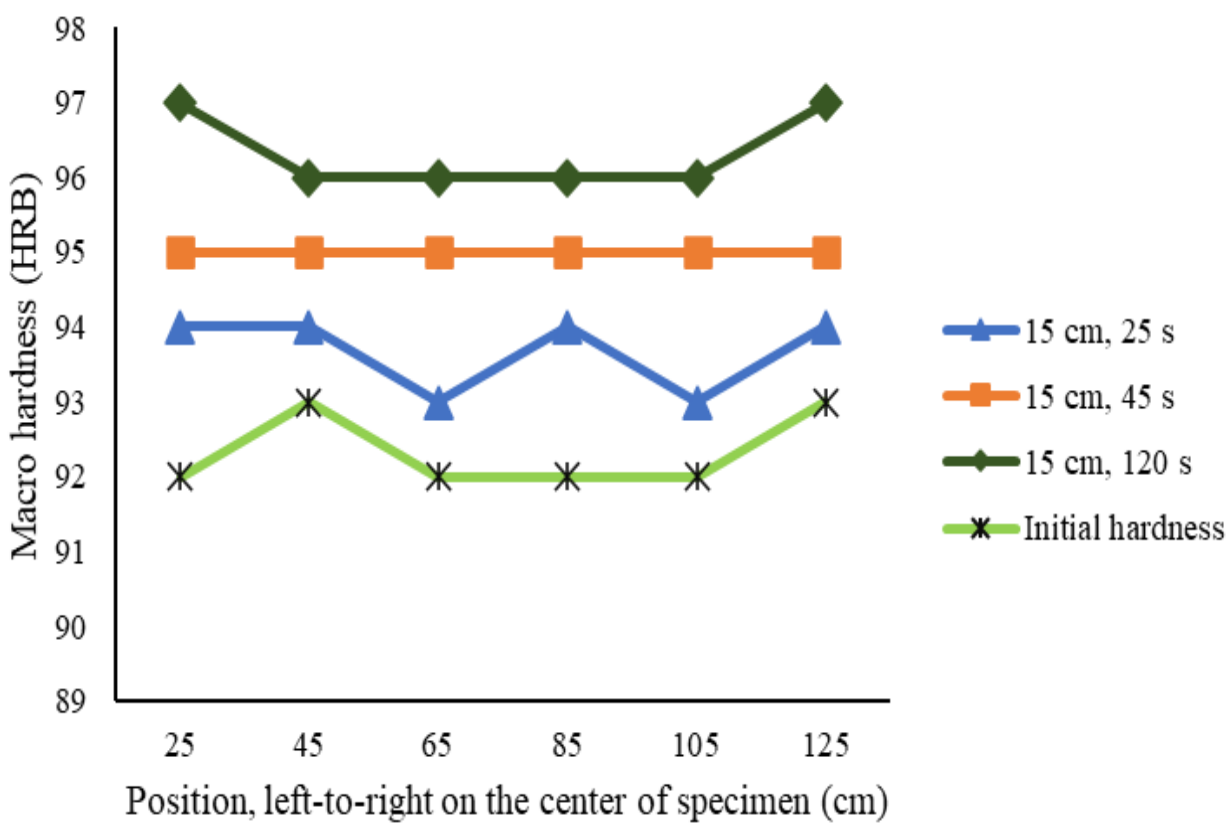

Figure 9. Rockwell hardness test results.

Comparing the micro-Vickers (on below the surface) with the Rockwell hardness values (on the surface), it appears that hardness measured by Rockwell hardness on the surface is underestimated. Both methods are typically used in the evaluation of mechanical performance analysis (Nandiyanto et al., 2021a; and Nandiyanto et al., 2021b). The maximum surface hardness value in Figure 9 is around 97HRB, while the micro hardness below the surface can reach as high as332 HV (108HRB) as shown in Figure 10. This phenomenon might because of the presence of valleys, hills, and granules on the surface, which decreased the total Rockwell hardness. 


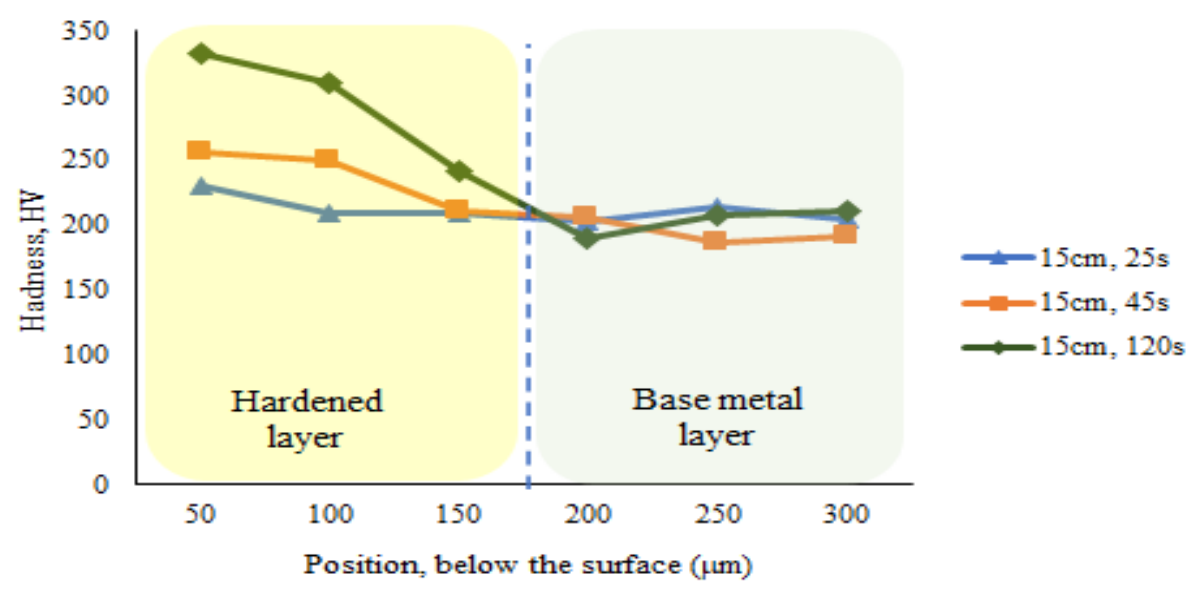

Figure 10. Micro-Vickers hardness test results.

\section{Paint Coating Thickness Test}

The sandblasting process will produce the roughness profile formation on the material surface in the form of hills and valleys. The roughness profile on the surface affects the bonding strength between the substrate of the surface and paint coating. More profound valleys and higher elevation on the surface will obtain a wide area and more durable interlocking between substrate and paint coating. Therefore, the rough surface produces thicker and more durable paint coating than a smooth surface.

In this study, to validate the surface characteristics resulting from the sandblasting process, a paint thickness test was performed. Sandblasting surface roughness affects the thickness of the paint that can be coated on a surface, for example, in the application of paint coating for cavitation damage prevention in fluid machinery [Hibi et al., 2018, Triawan et al., 2019]. Paint coating thickness was measured by the Elcometer 456 using the ASTMD 7091 standard. The width of the paint layer of the sandblasted surface used in this study is shown in Figure 11 as follows.

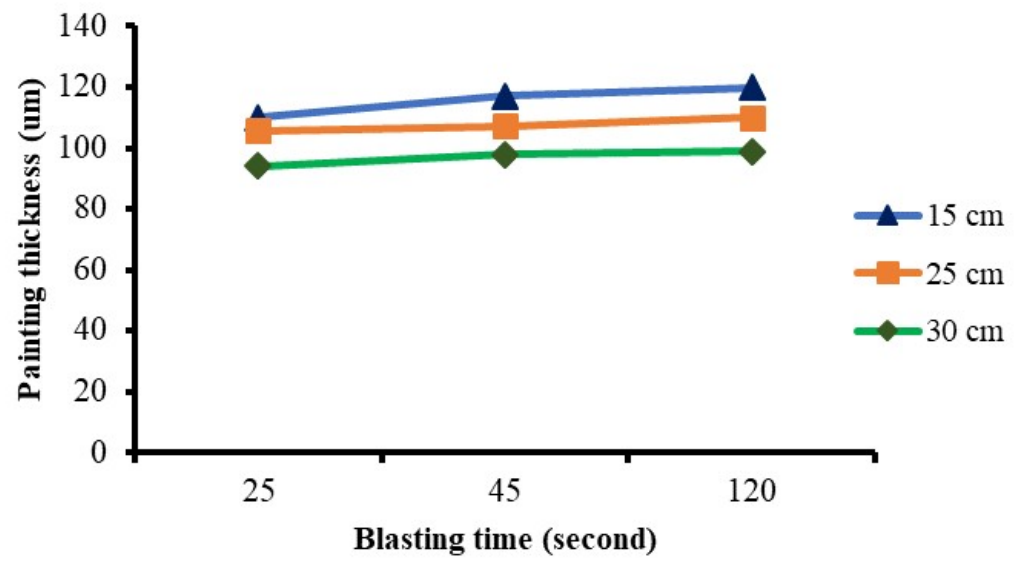

Figure 11. The result of paint coating test. 
Based on Figure 11, the highest paint thickness value occurs when the shooting distance is $120 \mu \mathrm{m}$ obtained from an experimental setup of $15 \mathrm{~cm}$, and the duration time is 120 seconds. And the lowest paint thickness value is $94.14 \mu \mathrm{m}$ obtained when the shooting distance is $30 \mathrm{~cm}$, and the shooting time is 25 seconds. Debonding driving forces decrease with increasing interface roughness and coating thickness, in which the critical value of point surface roughness value was Ra $4 \mu \mathrm{m}$, and the threshold of coating thickness was $34 \mu \mathrm{m}$ (Nazir, Khan, \& Stokes, 2015). Therefore, the lowest coating depth in this research $(94.14 \mu \mathrm{m})$ is higher than the critical value $(34 \mu \mathrm{m})$, and the lowest surface roughness $(\mathrm{Ra} 18.1 \mu \mathrm{m})$ is better than the threshold value $(\mathrm{Ra} 4 \mu \mathrm{m})$.

\section{CONCLUSION}

A study on the surface characteristics of low carbon steel JISG3101SS400 after the sandblasting process by steel grit G25 has been carried out in this research. The sandblasting pressure and angle are kept constant at 5 bars and $90^{\circ}$, respectively. The modified blasting parameters are nozzle-surface distance and blasting duration in order to investigate the effect of steel grit G25 as sand blasting particles. Based on the obtained results, it can be concluded that the steel grit G25 particle offered a good sandblasting effect on base metal low carbon steel SS400, which was indicated by the increasing surface hardness from 200 to $332 \mathrm{HV}$ with the depth of more than $50 \mu \mathrm{m}$. Moreover, the collision between particles and surface produced surface roughness, which may provide good bonding strength for painting applications. However, from the SEM observation, some micro-cracks are generated on the surface. This might decrease the surface strength and become the origin of crack initiation. The highest paint thickness value is when the steel grit abrasive material is $120 \mu \mathrm{m}$ with nozzle-to-surface distance of $15 \mathrm{~cm}$ and blasting time of 120 seconds, and the lowest paint thickness value is $94.14 \mu \mathrm{m}$ obtained from the nozzle-tosurface distance of $30 \mathrm{~cm}$ and a blasting time of 25 seconds. Both surface roughness and the thickness are higher than the critical values.

\section{ACKNOWLEDGMENTS}

We greatly acknowledge the support from PT. Gunung Baja Konstruksi, Indonesia, by providing the research facility and material for testing. ABDN acknowledges Ristek BRIN for Grant Penelitian Terapan Unggulan Perguruan Tinggi (PTUPT) and Bangdos Universitas Pendidikan Indonesia.

\section{REFERENCES}

Khorasanizadeh, S. 2010. The effects of shot and grit blasting process parameters on steel pipes coating adhesion.World Academy of Science, Engineering and Technology, 66: 1304-1312.

Triawan, F., Nandiyanto, A.B.D., Abdullah, A.G., \& Aziz, M. 2018. Plasma nitriding time on the hardness and crystal structure/phase of SUS403 and SCS6 martensitic stainless steels: An analytical study. Journal of Engineering, Science and Technology, 13(8): 2369-2378.

Trisnanto, S.R., Setiawan, I., Sunnardianto, G.K., \& Triawan, F. 2019. Stearic acid- modified CuO coating metal surface with superhydrophobicity and anti-corrosion properties. Journal of Engineering Research, (Special Issue2019): 63-75.

Saptaji, K., Afiqah, S.N., \& Ramdan, R.D. 2019. A Review on Measurement Methods for Machining Induced Residual Stress. Indonesian Journal of Computing, Engineering and Design (IJoCED), 1(2): 106-120.

Bedjaoui, A., Belaadi, A., Amroune, S., \& Madi, B. 2019. Impact of surface treatment of flax fibers on tensile mechanical properties accompanied by a statistical study. International Journal of Integrated Engineering, 11(6): 10-17. 
Arifvianto, B., Suyitno, K.A., \& Mahardika, M. 2012. Influence of grit blasting treatment using steel slag balls on the subsurface microhardness, surface characteristics and chemical composition of medical grade 316L stainless steel. Surface and Coatings Technology, 210: 176-182.

Bobzin, K., Ote, M., Linke, T.F., Sommer J., \& Liao, X. 2015. Influence of process parameter on grit blasting as a pretreatment process for thermal spraying. Journal of Thermal Spray Technology, 25(1): 1-9.

Ho, B.J., Tsoi, J.K.H., Liu, D., Lung, C.Y.K., Wong, H.M., \& Matinlinna, J.P. 2015. Effects of sandblasting distance and angles on resin cement bonding to zirconia and titanium. International Journal of Adhesion and Adhesives, 62: 25-31.

Miao, B., Song, L., Chai, Y., Wei, K., \& Hu, J. 2017. The effect of sandblasting pretreatment on plasmanitriding. Vacuum, 136: 46-50.

Multigner, M., Ferreira-Barragáns, S., Frutos, E., Jaafar, M., Ibáñez, J., Marín, P., Perez- Prado, M.T., González-Doncel, G., Asenjo, A., \& González-Carrasco, J.L. 2010. Superficial severe plastic deformation of 316LVM stainlesssteel through gritblasting: Effects on its microstructure and subsurface mechanical properties. Surface and Coatings Technology, 205(7): 1830-1837.

Chander, K.P., Vashista, M., Sabiruddin, K., Paul, S., \& Bandyopadhyay, P.P. 2009. Effects of gritblasting on surface properties of steel substrates. Materials and Design, 30(8): 2895-2902.

Permatasari, N., Sucahya, T.N., \& Nandiyanto, A.B.D. (2016). Agricultural wastes as a source of silica material. Indonesian Journal of Science and Technology, 1(1): 82-106.

Nandiyanto, A.B.D. (2018). Cost analysis and economic evaluation for the fabrication of activated carbon and silica particles from rice straw waste. Journal of Engineering Science and Technology, 13(6): 1523-1539.

Nandiyanto, A.B.D., Rahman, T., Fadhlulloh, M.A., Abdullah, A.G., Hamidah, I., \& Mulyanti, B. (2016). Synthesis of silica particles from rice straw waste using a simple extraction method. IOP Conference Series: Materials Science and Engineering, 128(1): 012040.

Ragadhita, R., Nandiyanto, A.B.D., Nugraha, W.C., \& Mudzakir, A. 2019. Adsorption isotherm of mesopore-free submicron silica particles from rice husk. Journal of Engineering Science and Technology, 14(4): 2052-2062.

Hibi, M., Triawan, F., Inaba, K., Takahashi, K., Kishimoto, K., Hayabusa, K., \& Nakamoto, H. 2018. Cavitation damage of epoxy resin subjected to uniaxial tensile loading. Mechanical Engineering Journal, 17-00151.

Triawan, F., Budiman, B. A., Nurprasetio, I.P., \&Sunnardianto, G. K. 2019. Direct and indirect measurement techniques of cavitation intensity: A brief review. Journal of Physics: Conference Series, 1402(4), 044048.

Nandiyanto, A.B.D., Triawan, F., Firly, R., Kishimoto, K. 2021a. Crystallite Size on Micromechanical Characteristics of WO3 Microparticles. Journal of Engineering Research, 9(3A): 268-277.

Nandiyanto, A.B.D., Hofifah, S.N., Girsang, G.C.S., Putri, S.R., Budiman, B.A., Triawan, F., \& Al-Obaidi, A.S.M. 2021b. The effects of rice husk particles size as a reinforcement component on resin-based brake pad performance: From literature review on the use of agricultural waste as a reinforcement material, chemical polymerization reaction of epoxy resin, to experiments. Automotive Experiences, 4(2): 68-82.

Nazir, M.H., Khan, Z.A, \& Stokes, K. 2015. Optimisation of interface roughness and coating thickness to maximise coating-substrate adhesion - A failure prediction and reliability assessment modelling, Journal of Adhesion Science and Technology, 29(14): 1415-1445. 